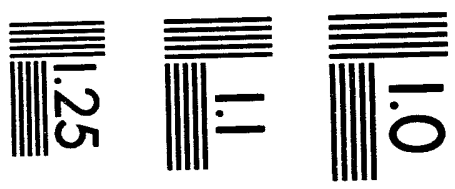

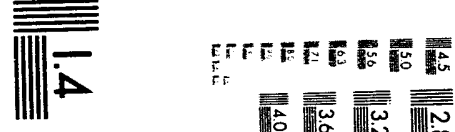

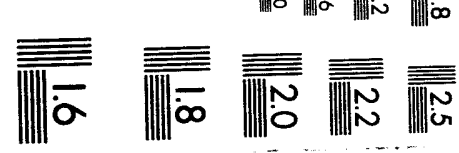



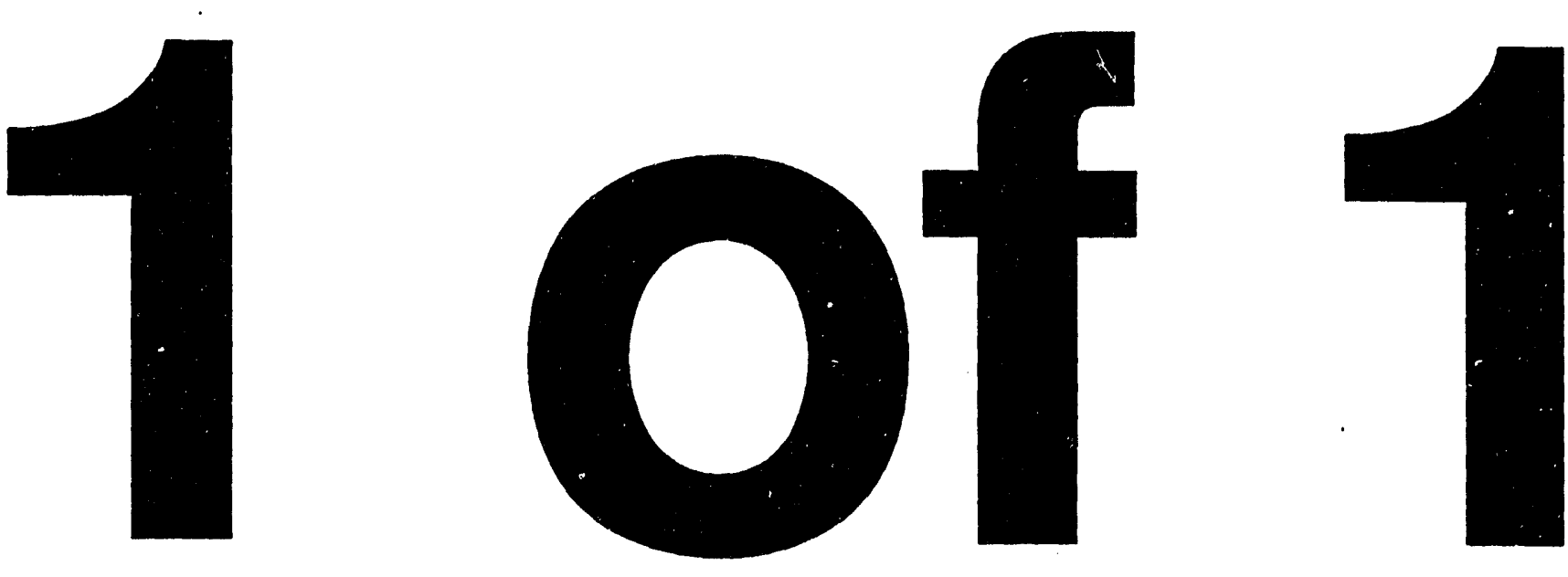


\title{
Conf-931018--84
}

UCRL-JC-114266

PREPRINT

\section{Structural Design of the Superconducting Poloidal Field Coils for the Tokamak Physics Experiment}

\author{
Thomas G. O'Connor and Jon P. Zbasnik
}

This paper was prepared for submittal to the Proceedings of the 15th Symposium on Fusion Engineering

Hyannis, MA

October 11-15, 1993

October 6, 1993

This is a preprint of a paper intended for publication in a journal or proceedings. Since changes may be made before publication, this preprint is made available with the understanding that it will not be cited or reproduced without the permission of the author. 


\section{DISCLAIMER}

This document was prepared as an account of work sponsored by an agency of the United States Government. Neither the United States Government nor the University of California nor any of their employees, makes any warranty, express or implled, or assumes any legal liability or responsibility for the accuracy, completeness, or usefulness of any information, apparatus, product, or process disclosed, or represents that its use would not Infringe privately owned rights. Reference herein to any specific commercial products, process, or service by trade name, trademark, manufacturer, or otherwise, does not necessarily constitute or Imply its endorsement, recommendation, or favoring by the United States Government or the Univeraity of Callfornia. The viewsand opinions of authors expressed herein do not necessarily state or reflect those of the United States - Government or the University of California, and shall not be used for advertising or 


\section{Structural Design Of The Supercondr :ting Poloidal Field Coils For The Tokamak Physi.s Experiment}

Thomas G. O'Connor, Jon P. Zbasnik

Lawrence Livermore National Laboratory, Livermore, CA, USA

\begin{abstract}
The Tokamak Physics Experiment concept design uses superconducting coils made from cable-inconduit conductor to accomplish both magnetic confinement and plasma initiation. The Poloidal Fleld (PF) magnet system is divided Into two subsystems, the central solenoid and the outer ring coils, the latter is focus of this paper. The eddy current henting from the puised operation is excessive for a case type construction; therefore, a "no case" design has been chosen. This "no case" design uses the conductor conduit as the primary structure and the electrical insulation (Iiberglass/epoxy wrap) as a structural adhesive. The model integrates electromagnetic analysis and structural analysis into the finite element code ANSYS to solve the problem. PF coll design is assessed by considering a variety of coll current wave forms, corresponding to various operating modes and conditions. The structural analysis shows that the outer ring colls are within the requirements of the fatigue life and fatigue crack growth requirements. The forces produced by the Toroldal Fleld colls on the PF colls have little effect on the maximum stresses in the PF colls. In addition in an efrort to reduce the cost of the coils a new elongated $P F$ coll design was proposed which changes the aspect ratio of the outer ring coils to reduce the number of turns in the coils. The compressive stress in the outer ring colls is increased while the tensile stress is decreased.
\end{abstract}

\section{INTRODUCTION}

The PF magnet system (see Fig. 1) for the Tokamak Physics Experiment (TPX) is described in more detail in [1]. The structural analysis of the outer ring coils includes analysis of the support structure as well as the winding pack structure. A similar analysis was done of the Central Solenoid and is presented in [2]. The winding pack

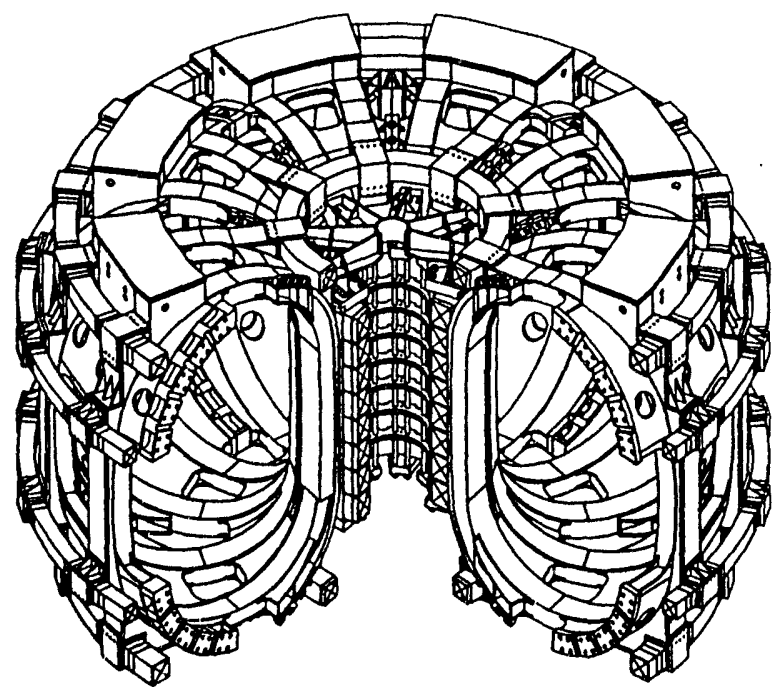

Fig. 1 Poloidal and Toroidal Field magnet assembly consists of cable-in-conduit conductor wrapped with a glass pack wrap insulation and separated by a polyimide sheet. The entire winding pack is wrapped with ground plane insulation.

In order to simplify the analysis of the PF coils, the complex winding pack structure is approximated as an orthotropic material or "smeared" mechanical properties. The "smeared" mechanical properties were calculated from a finite element model of the conduit and insulation [3]. In this model the local insulation is included around the exact geometry of the conduit. The conductor itself adds little stiffness to the winding pack and is not included in the model.

The finite element method was chosen for this analysis because the availability of commercial computer codes for simulation of magnetics, thermal, and stress problems. The analysis was carried out with ANSYS [4] , a finite element analysis code.

\section{MODEL DEVELOPMENT}

The outer ring coils are symmetrical top and bottom and are designated PF5-U, PF5-L, PF6-U, PF6-L, PF7-U, and PF7-L where $U$ is for upper and $L$ is for lower. Due to symmetry of the double null operation only the upper coils are analyzed and the upper and lower designation is dropped. The single null operation has lower coil currents and is not a critical case structurally. The coil modules are wrapped in a nominal $1 / 4$ inch thick ground wrap insulation (fiberglass/epoxy and polyimide material).

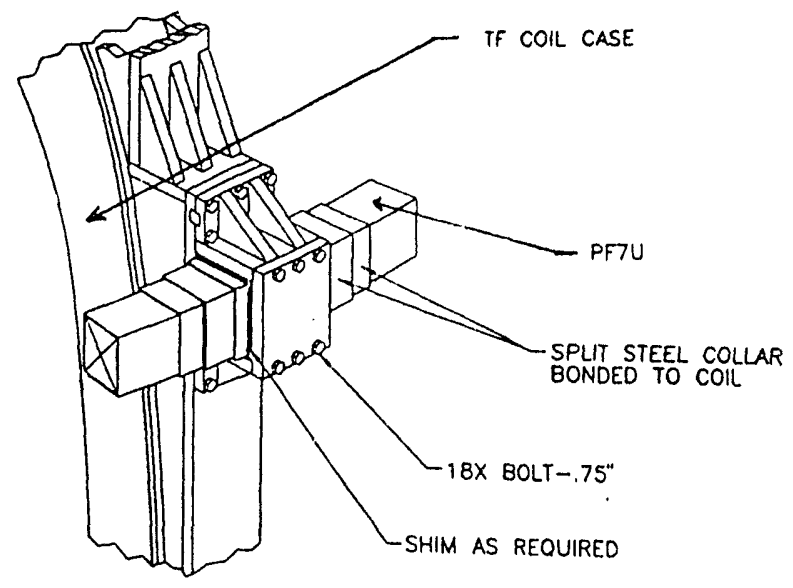

Fig. 2 Detail of the outer ring coil support structure 
After potting, the winding packs are clamped to the frame of the Toroidal Field (TF) structure. A split steel collar surrounds the coil at the support locations to better distribute the in-plane and out-of-plane bending, see Fig. 2.

The analysis was done in two steps, first the magnetic and then the structural. The 3-D magnetic model includes all of the PF and TF coils as well as the plasma, no symmetry was used. The model was used to solve for the Lorentz forces at 5 time steps: Prebias, Start of Flattop "SOF," Start of Burn "SOB," End of Burn "EOB," and End of Flattop "EOF," corresponding to the peak currents during one machine cycle. The Lorentz forces in the PF coils were calculated for three cases; 1 ) the PF coils and the plasma only, 2) the TF coils alone, and 3) the combination of case 1 and 2 . To reduce the overall calculation time the Lorentz forces were only calculated in 1/16th of PF5, 6 and 7, the spacing between the TF coils.

The 3-D structural model developed to analyze the outer ring coils is shown if Fig 3. Cyclic symmetry is used at each symmetry interface by coupling the nodal displacement degree of freedom at each interface. The winding pack is represented wilh directional orthotropic material properties calculated in [3]. The split steel collar was included to distribute the reastion load and was modeled as two $9.5 \mathrm{~mm}$ thick collars around the coil (see Fig. 4). The model was constrained vertically along the bottom surface of the stcel collar and radially at the outer radius of the steel collar. The model is used to estimate the stresses in the conduit, insulation, and support structure during cool-down and throughout the normal operation of the PF coils.

The outer ring coils are loaded through three mechanisms, thermally - during cool down, mechanically through rigid fixing of the outer ring coils to the TF coils, and magnetically - through Lorentz body forces. The PF coils are cooled from room temperature to $4 \mathrm{~K}$, a change of $289 \mathrm{~K}$, and then remain at $4 \mathrm{~K}$ for months at a time. The cool-down stresses presented do not include the effects of the split steel collar cool-down or the connection to the TF coils. The PF coil geometry, listed in Table I, and coil currents, shown in Fig. 5, are inputs into the magnetic model corresponding the base line design per the Conceptual Design Review.

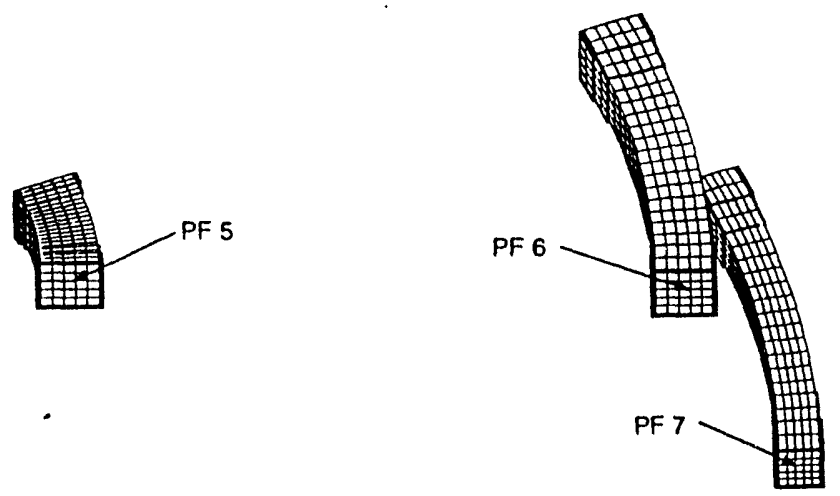

Fig. 3 3-D mesh of PF 5, 6, and 7 (base line design)
Table I

Poloidal Field coil geometry for the base line design [5]

\begin{tabular}{|c||c|c|c|c|}
\hline \multicolumn{1}{|c||}{$\begin{array}{c}\mathrm{PF} \\
\text { Coil }\end{array}$} & \multicolumn{4}{c|}{ Base line design } \\
\cline { 2 - 5 } & $\mathrm{r}_{\mathrm{c}}(\mathrm{m})$ & $\mathrm{z}_{\mathrm{c}}(\mathrm{m})$ & $\mathrm{dr}(\mathrm{m})$ & $\mathrm{dz}(\mathrm{m})$ \\
\hline \hline 5 upper & 1.233 & 2.200 & 0.239 & 0.239 \\
\hline 6 upper & 3.783 & 2.126 & 0.239 & 0.239 \\
\hline 7 upper & 4.244 & 1.091 & 0.167 & 0.191 \\
\hline
\end{tabular}

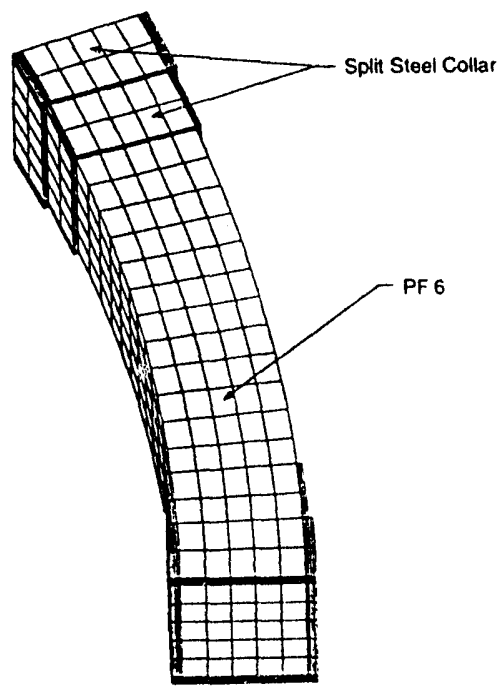

Fig. 4. 3-D mesh of PF6 showing the split steel collar

\section{RESULTS}

The Lorentz forces were calculated for 5 time steps corresponding to one machine cycle. A plot of the total vertical force as a function of time in each coil is shown in Fig. 6. The forces shown are a function of their own self field and the neighboring PF coils. The net vertical force due to TF coils on the outer ring coils is zero. Fig. 7 shows a comparison of the maximum Tresca stress with and without the effect of the TF coils. The magnetic field generated in the outer ring coils from the TF coils has little effect or the maximum Tresca stress and therefore little effect on the fatigue life of the coils. The increase in Tresca stress in PF7 and the decrease in PF5 and 6 is a function of the location in the coil and the coil current. The radial Lorentz burst force in the coils results in a hoop tension in the conduit. The maximum conduit hoop stress is shown in Fig. 8.

Due to the availability of "smeared" material data the conduit was assumed to made of Incoloy 908 even though PF 6 and 7 were suppose to be $316 \mathrm{LN}$ stainless steel. However, this should have little impact on the conclusions made in the paper.

The maximum Tresca stress in the outer ring coils is $260 \mathrm{MPa}$ which is well below the static stress allowable for Incoloy $\left(\sigma_{\text {allow }}=800 \mathrm{MPa}[6]\right)$. The PF coils are pulsed 


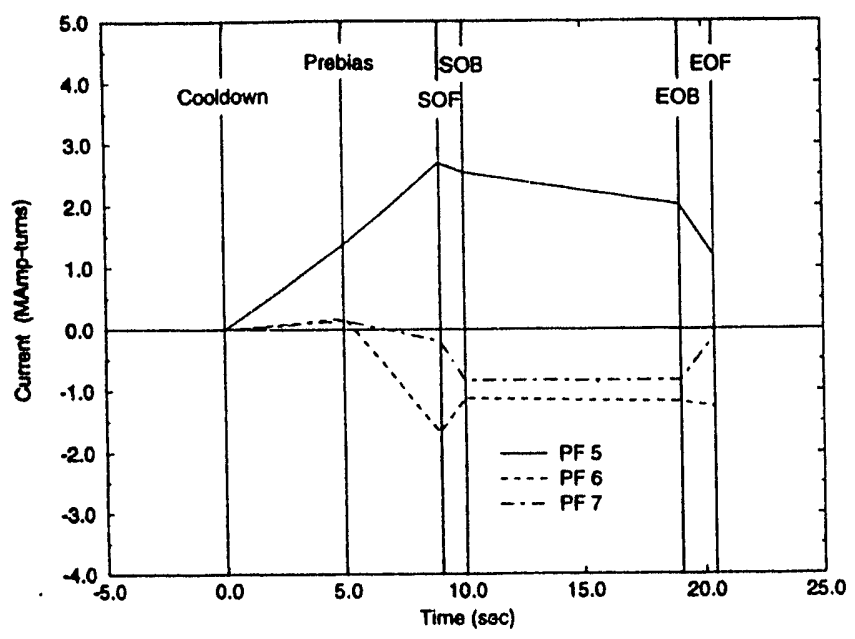

Fig. 5. Currents in the outer ring coils (base line design) [5]

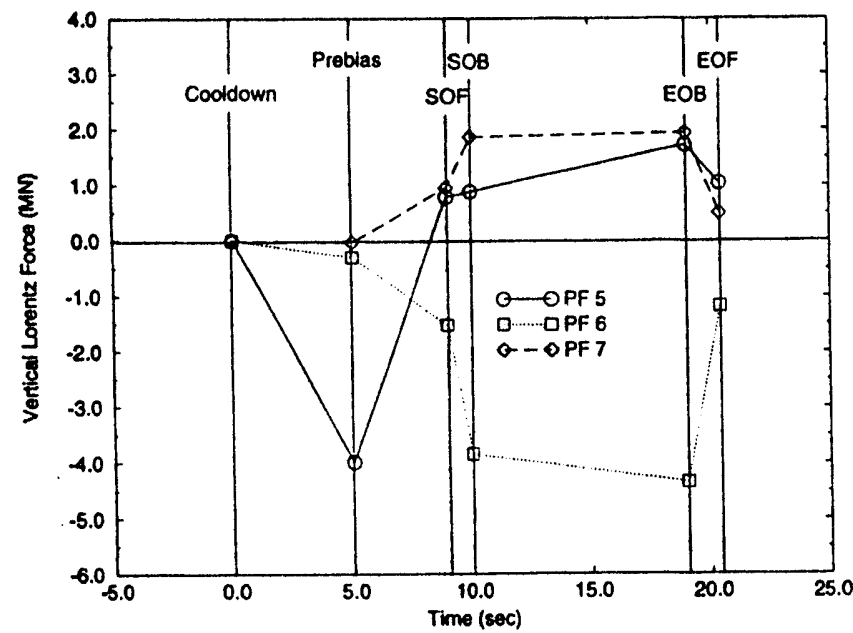

Fig. 6 Toal vertical force in the outer ring coils (base line design)

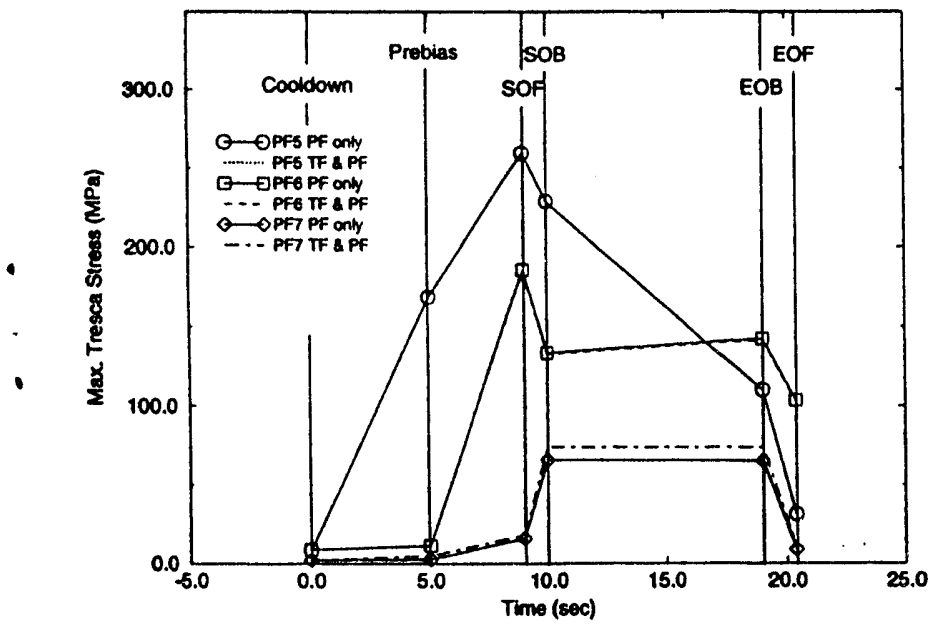

Fig. 7 Max. Tresca conduit stress in the outer ring coils (base line design)

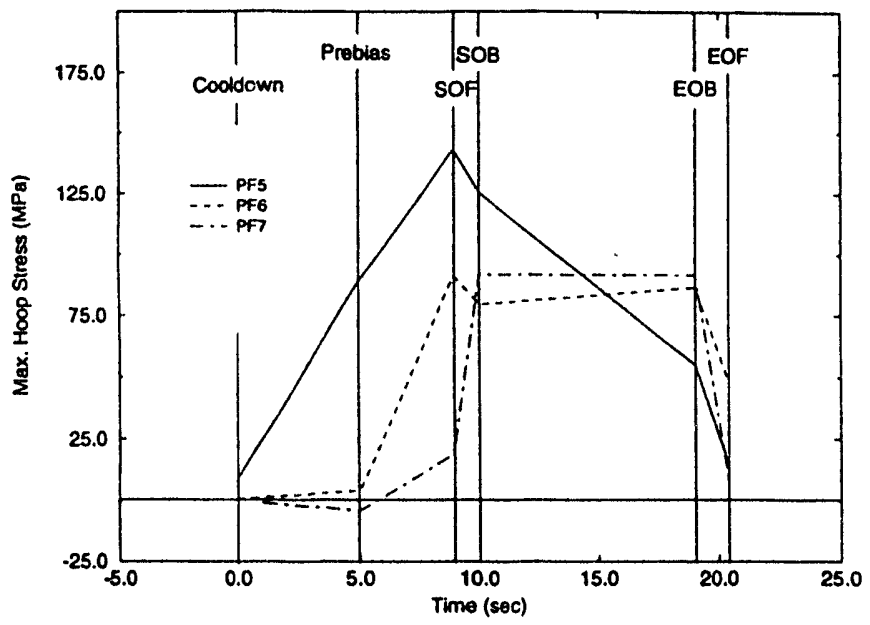

Fig. 8. Max. hoop conduit stress in the outer ring coils (base line design)

and are therefore subject to fatigue life and fatigue crack growth requirements. Over the life of the tokamak the PF magnet system is required to cycle through 30,000 machine cycles and 300 cool-down/warm-up cycles 7 . The 300 thermal cycles from room temperature to $4 \mathrm{~K}$ result in a generally small stress excursion which does little to affect the overall fatigue life. The maximum alternating Tresca stress of $250 \mathrm{MPa}$ taken from Figure 7 is well below the base metal allowable of $720 \mathrm{MPa}$ and the weld metal allowable of $680 \mathrm{MPa}$ [8].

Fatigue crack growth is controlled primarily by the maximum principle stresses. The hoop stress is in tension and is the main concern for fatigue crack growth. In Fig. 8 the hoop stress for each coil is plotted throughout one machine cycle including a cool-down cycle. Using the requirements in TPX Structural and Cryogenic Design Criteria Document [9] where the maximum permissible initial flaw size shall be governed by, as a minimum, two times the growth life experimentally determined based on component tests, or four times the growth life determinied based on material tests. An initial flaw size of $5 \%$ of the thickness of the conduit $(2.41 \mathrm{~mm})$ can be detected using an ultrasonic non-destructive test [10]. This initial crack size is quite small and may be pushing the limits of nondestructive testing, however, data was not available for crack sizes greater than $5 \%$ of the conduit wall thickness. The maximum stress range is $250 \mathrm{MPa}$ in PF 5. Using the $5 \%$ flaw size and the fatigue crack growth curves presented by $R$. Hoard et al. [11] for base metals a fatigue crack growth life of $1 \times 10^{6}$ can be determined. This easily satisfies the requirement that the fatigue crack growth life be four times the required life. The small deviations in the stress range experienced during cool-down and throughout one machine cycle have little affect on the overall life' of the machine for the present load case. Under the present load conditions the fatigue crack growth stress range allowable is 400 to $425 \mathrm{MPa}$.

The elongated PF coil design [12] changes the aspect ratio of the outer ring coils cross-section and will be 
referred to as Case- 0 throughout the rest of this paper. The Case- 0 coil geometry is listed in Table II and the 3-D mesh is shown in Fig. 9. A comparison of current (I), magnetic field $\left(B_{\max }\right)$, and total vertical force $\left(\mathrm{F}_{\text {ver }}\right)$ between the base line design and Case- 0 is listed in Table III. The maximum magnet field and vertical force is lower in Case0 . A comparison of the radial stress $\left(S_{r}\right)$, hoop stress $\left(S_{\theta}\right)$, and vertical stress $\left(S_{\mathrm{Z}}\right)$ between the base line design and Case- 0 is listed in Table IV. The maximum tensile stress in Case- 0 is lower than base line design which would improve the fatigue crack growth life. The maximum Tresca stress (see Table V) increased for Case-0 in PF5 and 7 which would reduce the fatigue life of these coils, however there is enough margin in the coils that the reduction in fatigue life will not be a problem.

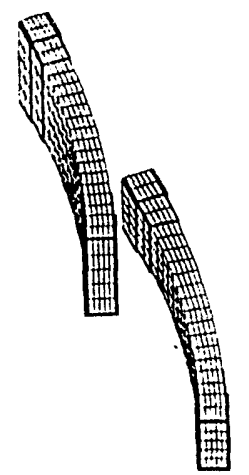

Fig. 9 3-D mesh of the outer ring coils (elongated coil design)

Table II

Poloidal Field coil geometry for the elongated design

\begin{tabular}{|c||c|c|c|c|}
\hline \multirow{2}{*}{ Coil } & \multicolumn{4}{|c|}{ Elongated design } \\
\cline { 2 - 5 } & $\mathrm{r}_{\mathrm{c}}(\mathrm{m})$ & $\mathbf{z}_{\mathrm{c}}(\mathrm{m})$ & $\mathrm{dr}(\mathrm{m})$ & $\mathrm{dz}(\mathrm{m})$ \\
\hline 5 upper & 1.253 & 2.224 & 0.191 & 0.287 \\
\hline 6 upper & 3.720 & 2.249 & 0.120 & 0.478 \\
\hline 7 upper & 4.220 & 1.138 & 0.120 & 0.287 \\
\hline
\end{tabular}

Table III

Comparison of coil winding pack current, $B_{\max }$, and vertical force between the base line design and the elongated design

\begin{tabular}{|c|c|c|c|c|c|c|}
\hline \multirow{2}{*}{$\begin{array}{l}\mathrm{PF} \\
\text { Coil }\end{array}$} & \multicolumn{3}{|c|}{ Base line design } & \multicolumn{3}{|c|}{ Elongated design } \\
\hline & $\begin{array}{c}\text { T } \\
\text { (MAmp } \\
\text { turns) }\end{array}$ & $\begin{array}{c}\mathrm{B}_{\max } \\
\text { (T) }\end{array}$ & $\begin{array}{l}\text { Fver } \\
\text { (MN) }\end{array}$ & $\begin{array}{l}\text { (MAmp- } \\
\text { turns) }\end{array}$ & $\begin{array}{l}B_{\max } \\
\text { (T) }\end{array}$ & $\begin{array}{l}\text { Fver } \\
(\mathrm{MN})\end{array}$ \\
\hline 5 & 2.010 & 3.174 & 1.7 & 2.015 & 3.081 & 1.6 \\
\hline 6 & -1.178 & 2.052 & -4.3 & -1.091 & 1.581 & -4.0 \\
\hline 7 & -0.831 & 1.779 & 1.9 & -0.948 & 1.782 & 1.7 \\
\hline
\end{tabular}

Table IV

Comparison of maximum and minimum stress between the base line design and the elongated design

\begin{tabular}{|c|c|c|c|c|c|c|}
\hline \multirow{2}{*}{$\begin{array}{l}\mathrm{PF} \\
\text { Ccil }\end{array}$} & \multicolumn{3}{|c|}{ Base line design } & \multicolumn{3}{|c|}{ Elongated design } \\
\hline & $\begin{array}{c}\mathrm{S}_{\mathrm{r}} \\
(\mathrm{MPa})\end{array}$ & $\begin{array}{l}\mathrm{S}_{\theta} \\
(\mathrm{MPa})\end{array}$ & $\begin{array}{l}S_{\mathrm{ver}} \\
(\mathrm{MPa})\end{array}$ & $\begin{array}{c}\mathrm{S}_{\mathrm{r}} \\
(\mathrm{MPa})\end{array}$ & $\begin{array}{c}\mathrm{S}_{\boldsymbol{\theta}} \\
(\mathrm{MPa})\end{array}$ & $\begin{array}{l}S_{\mathrm{ver}} \\
(\mathrm{MPa})\end{array}$ \\
\hline $\begin{array}{c}5 \max _{\min } \\
\text { X }\end{array}$ & $\begin{array}{r}44 \\
-117\end{array}$ & $\begin{array}{r}52 \\
-25\end{array}$ & $\begin{array}{r}50 \\
-63\end{array}$ & $\begin{array}{r}39 \\
-142\end{array}$ & $\begin{array}{r}40 \\
-31\end{array}$ & $\begin{array}{r}35 \\
-75\end{array}$ \\
\hline $\begin{array}{c}6 \max \\
\min \end{array}$ & $\begin{array}{r}33 \\
-207\end{array}$ & $\begin{array}{r}86 \\
-77\end{array}$ & $\begin{array}{r}76 \\
-178\end{array}$ & $\begin{array}{r}17 \\
-153\end{array}$ & $\begin{array}{r}69 \\
-153\end{array}$ & $\begin{array}{r}65 \\
-75\end{array}$ \\
\hline $\begin{array}{c}7 \max \\
\min \end{array}$ & $\begin{array}{r}23 \\
-107\end{array}$ & $\begin{array}{r}93 \\
-81\end{array}$ & $\begin{array}{r}86 \\
-128\end{array}$ & $\begin{array}{r}20 \\
-124\end{array}$ & $\begin{array}{r}93 \\
-77\end{array}$ & $\begin{array}{r}86 \\
-133\end{array}$ \\
\hline
\end{tabular}

Table V

Comparison of Tresca stress between the base line design ant the elongated design

\begin{tabular}{|c||c|c|}
\hline \multicolumn{1}{|c|}{ PF } & \multicolumn{2}{c|}{ Tresca Suress (MPa) } \\
\cline { 2 - 3 } Coil & Base line design & Elongated design \\
\hline 5 & 89 & 121 \\
\hline 6 & 132 & 109 \\
\hline 7 & 72 & 81 \\
\hline
\end{tabular}

\section{CONCLUSIONS}

- The outer ring coils meet the fatigue life and fatigue crack growth requirement for both the base line design and the elongated coil design.

- There increase in stress for elongated coil design is within the requirements for fatigue life and fatigue crack growth, therefore, structural integrity in not a limiting factor.

- The Lorentz forces resulting from the magnetic field from the TF coil does not affect the maximum Tresca stress in the outer ring coils

\section{ACKNOWLEDGMENT}

This work was perforned under the auspices of the U.S. Deparument of Energy by Lawrence Livermore National Laboratory under contract number W-7405-ENG48 and Princeton Plasma Physics Laboratory contract number DE-AC02-76-CHO3073.

\section{REFERENCES}

[1] W. Hassenzahl and T.G. O'Connor, ed., "TPX poloidal ficld system design description," March 12, 1993

[2] T.G. O'Connor and J.R. Heim, "Structural analysis of a superconducting central solenoid for the tokamak physics experiment,", IEEE MT-13 Conf. Victoria, Canada, Sept. 2024,1993

[3] T.G. O'Connor, "Smeared mechanical properties of the TPX central solenoid, LLNL , 14-930324-LLNL-TO'Connor-01, ASG-93-5.4-37, March 24, 1993

[4] ANSYS Revision 5.0, Swanson Analysis System, Inc., Houston, PA

[5] J. Schultz, "Memo - High Current Scenario," MIT, Feb 9, 1993

[6] ITER Magnet System, ITER Magnet System Design Unit, Document Series No. 26, International Atomic Energy Agency, Vienna, 1990

[7] W. Reiersen, ed., "TPX general requirements document," PPPL, March 15, 1993

[8] A. Nyilas, J. Zhang, B. Obst, and A. Ulbricht, "Fatigue and fatigue crack growth properties of $316 \mathrm{LN}$ and Incoloy 908 below 10K," Adv. in Cryo. Engr. Mat., vol. 38 , F.R. Fickett and R.P. Reed, Eds. New' York, 1992

[9] P. Heitzenroeder, ed., "TPX structural and cryogenic design criteria", PPPL, April 23, 1992

[10] G. Thomas and S. Benson, "Nondestructive evaluation of Incoloy 908 superconductor sheath material", unpublished

[11] R.W. Hoard and D.W. Stevens, "A comparison of the fatigue properties of Incoloy 908 and 316LN allows", LLNL, 13930326-LLNL-Hoard/Stevens-01, ASG-93-5.1-93, March 26, 1993

[12] R.H. Bulmer, "Poloidal field coil optimization - Case-0," LLNL memo, RHB93.74, September 24, 1993 

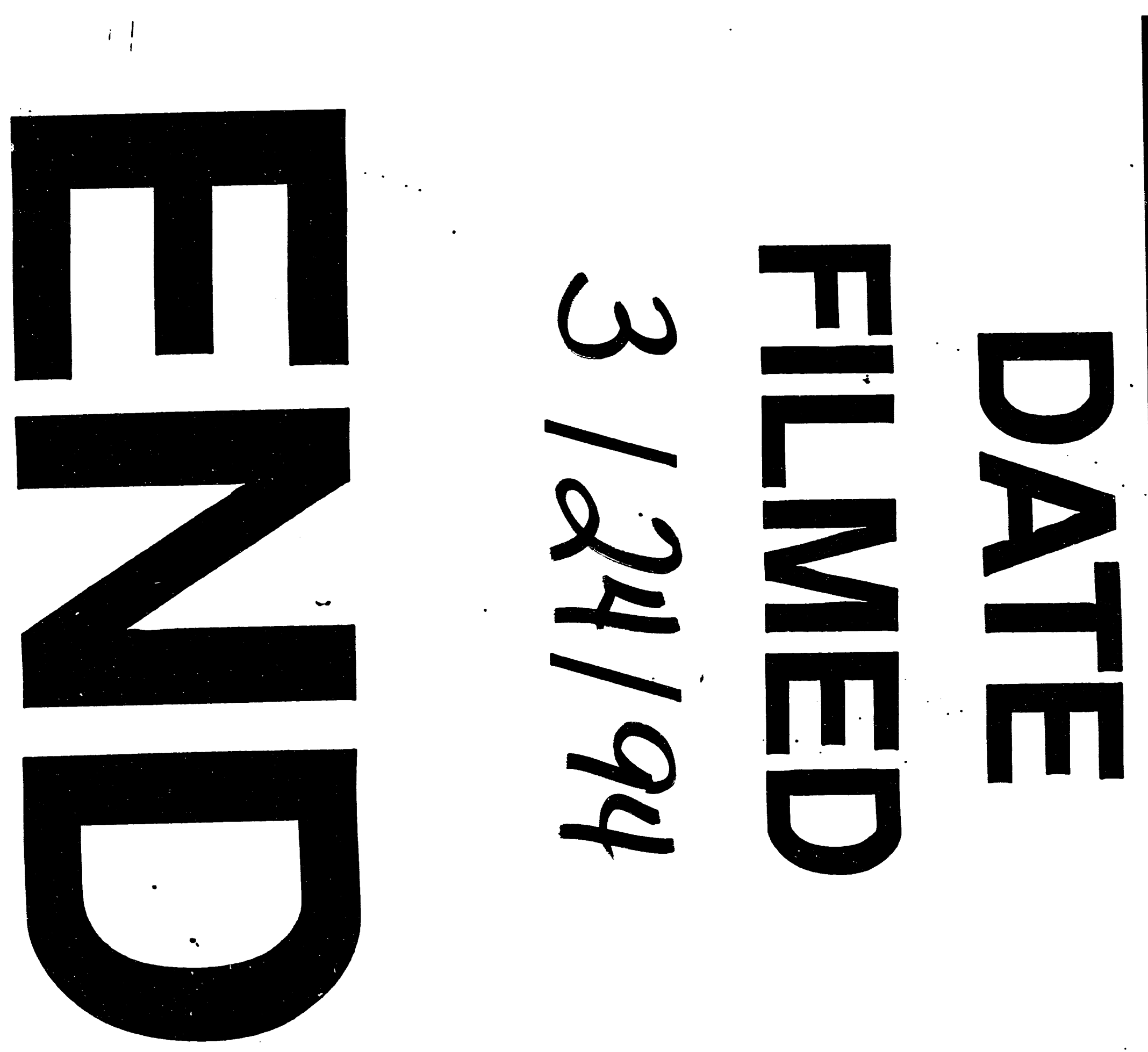


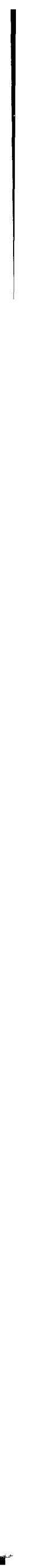

